\section{International Scientific Journal Theoretical \& Applied Science}

Bazarkul Bekbenbetova

Ph.D., Associate Professor, Eurasian National University named after LN Gumilev, Astana, Kazakhstan Zara 52@mail.ru

Akbota Maratovna Rakhmetova master student of the first course at the Faculty of Economics, majoring in "Economics", Eurasian National University named after LN Gumilev, Kazakhstan

SECTION 31. Economic research, finance, innovation, risk management.

\title{
INNOVATIONS IN THE DEVELOPMENT OF KAZAKHSTAN'S ECONOMY
}

Abstract: In article the main trends of development of national economy and questions of increase of investment activity. height.

Key words: innovative system, socio-economic progress trends, economic potential, productive sector, rates of

Language: Russian

Citation: Bekbenbetova B, Rakhmetova AM (2015) INNOVATIONS IN THE DEVELOPMENT OF KAZAKHSTAN'S ECONOMY. ISJ Theoretical \& Applied Science 04 (24): 166-170.

Soi: http://s-o-i.org/1.1/TAS*04(24)29 Doi: crossef http://dx.doi.org/10.15863/TAS.2015.04.24.29

\section{ИННОВАЦИОННЫЕ ТЕНДЕНЦИИ В РАЗВИТИИ ЭКОНОМИКИ КАЗАХСТАНА}

Аннотация: В статье рассматриваются основные тенденциии развития экономики страны и вопросы повышения инвестиционной активности.

Ключевые слова: инновационная система, тенденциии соцчильно-экономического развития, экономический потенциил, производственный сектор, темпы роста

\section{Введение}

Евразийский проект предполагает формирование стратегически мощного, экономически стабильного и выгодного всем странам участникам Евразийского экономического сообщества. Ядром нового интеграционного объединения должен стать Таможенный союз, где участниками являются Россия, Казахстан и Беларусь [1].

Инновационное развитие экономики и его влияние на повышение конкурентоспособности отраслей национального хозяйства широко обсуждается в зарубежной и отечественной экономической литературе. В зарубежной литературе эта проблема глубоко исследована и продолжает разрабатываться в научных исследованиях И.Шумпетера, М.Портера, Д.Белла, Ф.Махлупа, П.Друкера,, Дж.Робинсона и др $[2,3,4,5,6,7]$.

Научные основы высокотехнологичной экономики, которая предполагает наличие эффективной инновационной системы и создание институтов поддержки инновационного процесса исследованы в работах А.Кипшакбаева,
Е.З.Сулейменова, Н.В.Васильева, Ю.Шамрай , Т.Ю.Шемякина и других $[8,9,10,11,12]$.

«В начале второго десятилетия XXI века идея евразийской интеграции обретает реальные черты Единого экономического пространства. Она доказала свою историческую перспективность как верный путь к процветанию и благополучию наших стран и народов», отмечает Президент Казахстана в своей статье под названием «Евразийский Союз: от идеи к истории будущего»" [13].

Основные результаты исследования.

Одним из важных аспектов евразийского проекта является формирование стратегически мощного, экономически стабильного и выгодного всем странам участникам Евразийского экономического сообщества (ЕврАзЭс). Ядром нового интеграционного объединения должен стать Таможенный союз, где участниками являются Россия, Казахстан и Беларусь. Такое объединение усилий позволит нам не просто вписаться в глобальную экономику и систему торговли, но и реально участвовать в процессе выработки решений, задающих правила игры и 
определяющих контуры будущего», - считает В.В.Путин [14].

В этой связи, перед нашей страной стоит задача - войти до 2020 года в число инновационных экономик мира. Сегодня уже видны позитивные результаты введенных в действие новых предприятий по индустриальноинновационной программе страны за прошлые годы, как отмечал глава государства: «В 2010 году два из семи процентов роста экономики дали те 120 предприятий, которые мы в прошлом году ввели. В этом году надеемся на $2,6 \%$, то есть растет вклад индустрии, то, что мы сейчас делаем» [15] .

За годы независимости в стране объем ВВП (валовой внутренний продукт) выросло в 54,7 раза, которое с учетом достижении 2013 г., составил 1627,5 млрд. долл. А в 2013 году ВВП Казахстана составил 224.4 млрд.долл., (47 место в мире) и был на таком же уровне, как ВВП Ирландии, Португалии, Пакистана.

По отношению к ВВП России за 1992-2010 годы он увеличился на $3,4 \%$, Узбекистана $147,9 \%$ и Украины - на $32,8 \%$, что практически достиг ее уровня. Соответственно изменилась динамика ВВП на душу населения. За 1990-2013 годы данный показатель вырос в 7.4 раза и составил 13650 долларов. И на сегодняшний день Казахстан входит (по данным ООН за 2008 г.) в группу стран с уровнем доходов выше среднего [16].

Тенденции социально-экономического развития страны в 2010 - 2013 годах подтверждают что рост экономических показателей был достигнуто, во - первых, за счет благоприятной ситуаций на мировом рынке сырьевых ресурсов, во-вторых, растущим спросом на товары казахстанского экспорта вследствие подъема экономики в странах ЕС и

Китая. В-третьих, на основе ввода в действие новых производственных мощностей в рамках государственной программы индустриализации.

За анализируемые 2006-2013 годы, в добывающей отрасли удельный вес экспорта составил от $75,5 \%$ до $76,3 \%$, когда за тот же период импорт данного продукта равнялся $14,1 \%$ и $11,2 \%$, соответственно.

По обрабатывающей промышленности за этот же период экспорт составил соответственно $24,5 \%$ и 20,4\%, когда импорт продукции этой категории был равен $85,9 \%$ и $88,8 \%$, соответственно [16].

Объем всей промышленной продукции в реальном выражении 2013 году по сравнению с 2007 годом снизилась на 13\%, а с 2010 на 7,1\%, из них горнодобывающая - на 12,3\% (2013/2007) и 2,6\% (2013/2010), таблица 1.

Индекс физического объема производства в обрабатывающей промышленности в 2013 году по сравнению с 2001 годом снизился с $115 \%$ до 101,9\%. В 2010 - 2013 годы, также идет снижение показателя с 113,9\% до 101,9\%. Что и подтверждает имеющиеся проблемы данного сектора, которые надо решать.

Таблица 1

Индексы физического объема промышленной продукции по отраслям в \% к предыдущему году*

\begin{tabular}{|l|c|c|c|c|c|c|c|}
\hline \multicolumn{1}{|c|}{ Наименование } & 2007 & 2008 & 2009 & 2010 & 2011 & 2012 & 2013 \\
\hline \multicolumn{1}{|c|}{ Вся промышленность } & 115,5 & 113,8 & 101,7 & 109,6 & 103,8 & 100,7 & 102,5 \\
\hline Электроэнергетика & 105,8 & 108,6 & 97,8 & 105,3 & 106,5 & 104,7 & 101,5 \\
\hline Нефтедобывающая & 115,8 & 115,1 & 109,1 & 105,8 & 100,5 & 98,9 & 103,2 \\
\hline Нефтеперерабатывающая & 103,8 & 123,7 & 107,7 & 114,2 & 100,9 & 100,5 & 103,3 \\
\hline Газовая & 125 & 101,5 & 103,4 & 106,2 & 105,8 & 106,3 & 103,7 \\
\hline Угольная & 128,4 & 105,7 & 92,1 & 104,4 & 106,0 & 101,8 & 100,0 \\
\hline Черная металлургия & 110,8 & 101,8 & 94,1 & 109,4 & 106,8 & 88,2 & 90,8 \\
\hline Цветная металлургия & 149,8 & 113,6 & 94,4 & 115,7 & 108,2 & 107,2 & 98,8 \\
\hline Химическая и нефтехимическая & 122,2 & 161,3 & 76,3 & 121,4 & 130,1 & 103,2 & 102,6 \\
\hline Машиностроение и металлобработка & 179,9 & 141,2 & 85,7 & 133,6 & 119,0 & 116,5 & 116,6 \\
\hline $\begin{array}{l}\text { Промышленность } \\
\text { материалов }\end{array}$ & 138,6 & 146,1 & 107,6 & 136,9 & 125,8 & 108,7 & 99,1 \\
\hline Легкая промышленностьльных & 122,5 & 205,9 & 87,6 & 100,5 & 83,3 & 108,1 & 98,0 \\
\hline Пищевая промышленность & 116,1 & 108,2 & 98,8 & 105,8 & 100,7 & 102,5 & 102,5 \\
\hline *Рассчитано на основе данных Агентства РК по статистике, опубликованных на интернет-сайте www.kazstat.asdc.kz \\
\hline
\end{tabular}


Но, надо отметить, что увеличение годового оборота промышленного производства в целом, способствовало росту объема предоставляемых услуг транспорта. При этом, услуги транспорта по итогам года выросли на $7,4 \%$ за счет увеличения грузооборота, как по внутренним, так и внешним направлениям. Производство услуг в экономике по итогам 2010 года увеличилось на 7,1\%, в том числе услуги связи выросли на 5,0\%.

Увеличение уровня потребительского спроса за счет роста реальных доходов населения в 2013 году на $6,3 \%$ и замедления инфляционных процессов в экономике, создало основу для роста объемов торговли. Ее уровень в реальном выражении по итогам года увеличилась на 13,5\% по отношению к предыдущему году.

В целом, объем внешнеторгового оборота определился на уровне 89,9 млрд. долл. США, в том числе - экспорт составил 59,5 млрд. долл. США, импорт 30,4 млрд. долл. США. Соответственно, объем экспорта по отношению уровня 2009 года увеличился на $37,8 \%$, а импорта на $7,0 \%$.

Нужно отметить, что уровень инфляции в стране по итогам 2013 года составила 6,2\%, что на 1,6\% ниже уровня этого показателя за 2010 год. Способствовали данному процессу повышение цен на продовольственные товары на $10,1 \%$, на непродовольственные товары - 5,5\% и на платные услуги - 6,8\% .

За 2010-2013 годы, замечается значительное улучшение макроэкономического потенциала страны за счет стабильного роста мировых цен на нефть, что дало возможность сформировать достаточный уровень доходов государственного бюджета и на этой основе обеспечить увеличение расходов по отношению к предыдущему году.

Таким образом, увеличение доходов государственного бюджета в истекшем году достигнуто за счет, обоснованного роста уровня развития отраслей экономики и составляет $31,6 \%$ по отношению к 2010 году.

Особо отметим, что в данном году инвестиционная активность восстанавливалась более медленнее, чем производство товаров и услуг в секторах экономики, что поясняется большей инерционностью этого показателя. За 2008 - 2010 годы инвестиции в основной капитал сократились на $0,5 \%$, а по отношению к уровню 2007 года разница составила порядка $11 \%$. Значение данного показателя в 2013 году составило 6072687 млн.тг, что на $30 \%$ выше значений 2010 года [17].
Самым быстро развивающимся (темпы роста составляли $5,7 \%$ ) и потому чрезмерно уязвимым началу кризиса 2007 года был строительный сектор. Следовательно, в первую очередь кризису подверглись рынок недвижимости и строительство новых объектов. Впоследствии, многие из них были заморожены, что и стало первопричиной резкого снижения инвестиционной активности в стране. Для сравнения, если доля инвестиции на строительство в общем объеме инвестиции в основной капитал в 2008 году составляла 10,7\%, то 2013 году она равнялась $1,3 \%$.

Результаты эффективного развития производственного сектора экономики положительно отразились и на рынке труда. В 2010 году уровень безработицы снизилось до $5,8 \%$ по отношению к экономически активному населению против 6,6\% в 2009 году. Здесь положительно сказались и меры предпринятые Правительством Казахстана по регулированию последствий финансового кризиса путем реализации программы Дорожная карта.

В 2011 году, по данным ведомства, правительство продолжит работу по реализации отраслевых программ в приоритетных секторах экономики и поддержки бизнеса: «Экспорт 2020», «Инвестор-2020», «Дорожная карта 2020». Также в этом году запущена программа «Производительность - 2020». Разработанная Карта индустриализации - это 469 проектов стоимостью 8,3 триллиона тенге. В рамках проекта будут созданы более 140 тысяч рабочих мест. До конца года в стране планируется, запустит до 130 проектов на сумму более 600 миллиардов тенге. По всем проектам Карты индустриализации привлекут инвестиций на сумму около 1,5 триллионов тенге [18].

Если говорить о новых тенденциях в развитии экономики Казахстана, то нужно обратиться к выступлению Президента страны Н.А.Назарбаева на индустриальноинновационном форуме «Сильный Казахстан построим вместе!», который состоялся 4 июля 2011 года в г. Астане. «... Мы видели сами, что получается, когда меняются цены на мировом рынке нефти, газа, металлов. Мы не можем постоянно сидеть и зависеть от этого. Мир ищет сейчас новые виды энергии и будет находить, и мы должны к этому готовиться», - отметил президент Казахстана [19].

Выступая на индустриально-инновационном форуме, президент страны определил пять действенных тенденций инновационного развития экономики страны.

Во-первых, было отмечено роль новых технологии в обеспечении энергоэффективности, и в этой связи, необходимость нормативных 
актов, регламентирующих процесс перехода на новые энергосберегающие основы.

Во-вторых, должны взять курс к эффективному развитию производства несырьевого сектора. Это - машиностроение, строительная индустрия, химическая и фармацевтическая промышленность и др.

Третья тенденция предусматривает модернизацию агропромышленного комплекса. В этом направлений за прошлые годы сделано было не мало. Теперь же стоит задача, выйти на новый уровень по экспорту мяса, овощей и фруктов.

Четвертая тенденция - продуктивное развитие малого и среднего бизнеса на основе ввода новых проектов. Малый и средний бизнес должны обеспечить основу устойчивого развития экономики страны, и работать по примеру Германии выпуская 85\% всей продукции по стране. В своем выступлении Президент подчеркнул, что развитие МСБ - это важная политическая задача.

Пятая тенденция о необходимости повышения производительность труда. Для повышения производительности в Казахстане созданы необходимые условия. Функционирует система микрокредитования в рамках программ «Занятость-2020», «Дорожная карта бизнеса2020», фонда «Даму», «КазАгро» и другие кредитные линии. В то же время, Президентом предложена программа «Народного IPO», детали которой прорабатываются Правительством .

Эти пять тенденции обозначенные Президентом страны реально открывают путь к новому этапу инновационного развития Казахстана и обеспечивают возможность достижения высоких качественных результатов, как экономики в целом, так и отдельных отраслей национального хозяйства, в частности.

\section{Заключение}

Задача страны - войти до 2020 года в число инновационных экономик мира. Но это огромная работа по разработке и внедрению в производство новых технологии; модернизации основ развития отрасли национального хозяйства, по определению схем действия финансовых программ и другое. Как отмечено выше, есть положительные результаты индустриальноинновационных программ, так в 2010 году два из семи процентов роста экономики обеспечили предприятия, которые были введены в действие в 2009 году. В 2011 году по данному пункту рост составил два с половиной процента, то есть повышение вклада индустрии в экономику страны подтверждается своими фактическими результатами. А к 2015 году, согласно Стратегии - 2020 ожидается, что активное проведение индустриально-инновационной политики, обеспечит темпы роста экономики не менее чем на $8,8-9,2 \%$ в год.

\section{References:}

1. Mansurov T (2011) "Eurasian Project Nursultan Nazarbayev, Embodied In The Life", Kazakhstanskaya Pravda, December 6, 2011.

2. Schumpeter JA (1982) Theory of Economic Development / Translated from the German Avtonomova, B.C., Lyubskiy, M.S., Chepurenko A.Y.-M., 1982. 455 p.

3. Porter M (2005) Competitive Advantage: How to Achieve High Results and Ensure Its Sustainability/ Translated from English, 2005.

4. Bell D (1999) The Coming of Post-industrial Society: a Venture in Social Forecasting / Translated from English. Ed. Inozemtseva, V.L. - Moscow: Academia, 1999.

5. Machlup F (1962) The Production and Distribution of Knowledge in The United States. - Princeton, 1962.

6. Peter F (2007) Drucker Innovation and Entrepreneurship / Translated from English. Moscow: Publisher: Williams, 2007.

ISPC The Combination of Technology \&

Education, Östersund, Sweden
7. Robinson J (1986) The Economics of Imperfect Competition, Translated from English Moscow: Progress, 1986. - 253 p.

8. Kipshakbayev A (2005) The Role of the Center for Engineering and Technology Transfer in Industrial-Innovative Development of Kazakhstan. Industry of Kazakhstan. №4. Almaty, 2005.

9. Suleimenov EZ, Vasilyeva NV (2006) Innovative activity in the Republic of Kazakhstan: Analytical review- Almaty, 2006.

10. Fokin S (2000) Trends in The Development of Innovative Processes in Russian EconomyMoscow, 2000.

11. Shamrai Y (2009) Innovation and Competitiveness of The National Economy: a Modern Approach. Problems of the Theory and Practice of Management. - 2009. - № 2.

12. Shemyakina TY (2007) The Innovation Process: Regulation and Management. Moscow: Publishing house "Flint". 2007. 
13. Nazarbayev NA (2011) "Eurasian Union: from the Idea to The History of The Future." "Izvestia", 25 October 2011.

14. Putin VV (2011) "Eurasian Union will Ensure Success and Prosperity". "Izvestie", October 4, 2011.

15. (2010) The Strategic Plan for Development of the Republic of Kazakhstan until the year 2020. Approved by the Decree of the President of the Republic of Kazakhstan № 922 of February 1, 2010.

16. Bekbenbetova B (2015) "Priorities of Structural Modernization of Kazakhstan's Economy: Theory and Practice Implementation."
Monograph. - Astana: ENU. L.N.Gumilyov, 2015. - $212 \mathrm{pp}$.

17. (2010) Statistics Agency of Kazakhstan. Kazakhstan in the 2010. Astana: Statistical Yearbook. Available: www.stat.gov.kz (Accessed: 20.04.2015).

18. (2010) Government of Kazakhstan. The Program «Business Road Map-2020». Available: http://ru.government.kz/resources/docs (Accessed: 20.04.2015).

19. Nazarbayev NA (2011) "Strong Kazakhstan will Build Together". Industrial Innovation Forum. Astana, July 4, 2011. 